\title{
Análise comparativa multicriterial de estratégias em sustentabilidade urbana aplicada aos bairros de Cidade Pedra Branca (Palhoça, SC) e Vauban (Freiburg, Alemanha)
}

\author{
Multi-criteria comparative analysis of urban sustainability \\ strategies applied to Cidade Pedra Branca (Palhoça, SC) \\ and Vauban (Freiburg, Germany)
}

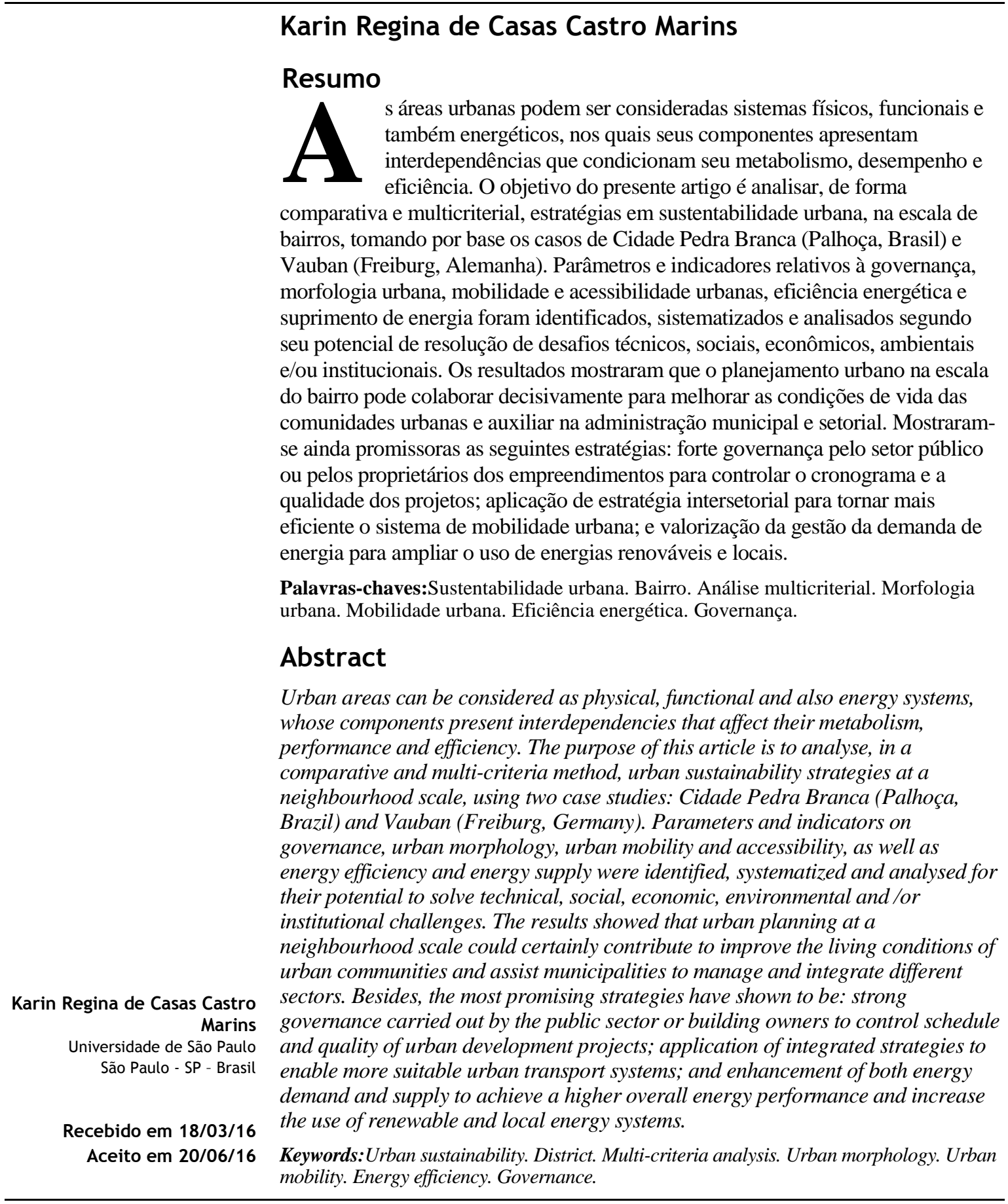

MARINS, K. R. de C. C. Análise comparativa multicriterial de estratégias em sustentabilidade urbana aplicada aos bairros de Cidade Pedra Branca (Palhoça, SC) e Vauban (Freiburg, Alemanha). Ambiente Construído, Porto Alegre, v. 16, n. 4, p. 393-408, out./dez. 2016. ISSN 1678-8621 Associação Nacional de Tecnologia do Ambiente Construído. http://dx.doi.org/10.1590/s1678-86212016000400141 


\section{Introdução}

"As áreas urbanas podem ser consideradas sistemas físicos, funcionais e também energéticos, nos quais seus componentes apresentam interdependências que condicionam seu metabolismo [...]" (MARINS; ROMÉRO, 2012, p. 118), desempenho e eficiência. O conceito de "sistema" enfatiza a ideia de um conjunto de componentes que são interconectados para alcançar um objetivo definido e que necessitam de constante avaliação de desempenho ou de eficiência. Assim, a abordagem integrada ou sistêmica no planejamento e desenho de áreas urbanas se coloca atualmente como uma necessidade no contexto da crescente urbanização, das imposições relacionadas à escassez de recursos e da promoção de inclusão social, como parte dos esforços globais para se atingirem padrões de vida, produção e consumo mais adequados aos paradigmas do desenvolvimento sustentável.

De acordo com Batty (2008), as cidades, enquanto sistemas, passaram a ser consideradas conjuntos de elementos ou componentes ligados por conjuntos de interações. A estrutura arquetípica foi configurada em torno do uso do solo, considerando as conexões econômicas e funcionais entre os diversos usos. De acordo com Deakin, Curwell e Lombardi (2002 ${ }^{1}$ apud DANIELL et al., 2005), o planejamento e a gestão de áreas urbanas de acordo com critérios de sustentabilidade prescindem de uma visão clara do sistema urbano e das interações de seus subsistemas. Entre eles são reconhecidos os subsistemas técnicos urbanos, compostos da infraestrutura e dos serviços públicos (MARTIRNAD, 1986), além do uso e da ocupação do solo. De acordo com Walton et al. (2007), a abordagem integrada em planejamento urbano requer, primeiramente, a avaliação e o desenvolvimento de interconexões mais do que adicionar "elementos verdes" ao ambiente construído. Complementando, o autor menciona que isso não demanda necessariamente soluções que alterem a paisagem urbana, mas que permitam modificar a dinâmica das cidades. Segundo o autor, uma forma de revelar as interdependências entre os condicionantes urbanos é por meio do estabelecimento de "ciclos virtuosos".

Para Bourdic, Salat e Nowacki (2012), a sustentabilidade urbana está profundamente relacionada à morfologia urbana, pois, além de relevante do ponto de vista socioeconômico e

${ }^{1}$ DEAKIN, M.; CURWELL, S.; LOMBARDI, P. Sustainable Urban Development: the framework and directory of assessment methods. Journal of Environmental Assessment Policy and Management, Imperial College Press, v. 4, n. 2, p. 171-197, June 2002. ambiental, ainda permite realizar uma abordagem integrada e sistêmica de seus elementos. De acordo com Marins e Roméro (2012), a forma urbana é resultado da combinação de diversos elementos que formam as áreas ocupadas, livres, com vegetação ou pavimentação, com volumetrias, materiais e cores diversas. A forma urbana impacta nas funcionalidades, na qualidade e no desempenho do espaço urbano, condicionando as densidades construída e populacional, assim como a demanda por infraestrutura e serviços nas cidades (NG, 2010). O planejamento e o projeto urbano prescindem, portanto, de reconhecer e incorporar as múltiplas interações dos elementos urbanos.

A forma urbana, por outro lado, está física e funcionalmente integrada aos subsistemas técnicos urbanos. Estes, por sua vez, são responsáveis por propiciar transporte e circulação de pessoas e mercadorias, bem como fornecimento de água e energia, transmissão de dados e coleta e tratamento de esgotos e resíduos. Há profunda interdependência entre esses elementos no que tange à densidade demográfica e à capacidade dos sistemas, formas de uso e ocupação do solo e características das redes de infraestrutura. Assim, as condições nas quais se dão as inter-relações impactam na eficiência e na qualidade de cada um desses elementos e da área urbana como um todo, em termos econômicos, sociais e ambientais.

Recentemente, no âmbito da sustentabilidade urbana, diversas pesquisas redirecionaram seu foco da escala da cidade para a escala do bairro, cujo planejamento pode incorporar estratégias para resolver os problemas na escala da cidade (ENGEL-YAN et al., 2005). Segundo Wheeler (2013), a escala do bairro cria as condições e os ambientes favoráveis para representar uma das mais promissoras áreas para o desenvolvimento sustentável. Além disso, na abordagem sistêmica em áreas urbanas, as análises multicriteriais têm sido valorizadas, uma vez que permitem adotar uma ação correspondente a cada critério elencado (BERARDI, 2012).

Distritos urbanos configuram, em geral, áreas administrativas municipais, compostas de diversos bairros e unidades de vizinhança. No município de São Paulo, por exemplo, distritos localizados nas regiões mais urbanizadas têm cerca de 600 a 800 hectares. Segundo Walton et al. (2007), uma unidade de vizinhança tem cerca de 50 hectares e deve estar organizada de forma integrada e dinâmica para proporcionar acesso a facilidades cotidianas, com variedade suficiente de meios de locomoção, sobretudo da caminhada, bem como 
disponibilizar lugares e espaços para a realização das diversas atividades.

De acordo com Yan, Wong e Jusuf (2013), a incorporação de princípios de sustentabilidade no projeto de unidades de vizinhança é importante porque muitos dos problemas identificados na escala macrourbana se referem a efeitos acumulados do planejamento ineficiente na microescala. Segundo os autores, esse fato se torna evidente ao se considerar a tradicional dependência das áreas urbanas de sistemas centralizados de infraestrutura urbana. A análise em microescala, por sua vez, é importante para desenvolver soluções locais para os vários sistemas urbanos. Os sistemas distritais podem, ainda, se tornar mais viáveis em relação a sistemas individuais, sendo o planejamento e a gestão pública facilitados pela existência, em geral, de uma unidade administrativa nessa escala.

O objetivo do presente artigo é analisar, de forma comparativa e multicriterial, estratégias em sustentabilidade urbana, na escala de distritos, bairros e unidades de vizinhança, previstas e implantadas em dois locais selecionados, os bairros de Cidade Pedra Branca (Palhoça, Santa Catarina, Brasil) e Vauban (Freiburg, Alemanha). Trata-se de bairros em implantação no Brasil e no exterior respectivamente, projetados com o intuito de atingir níveis mais elevados de qualidade, desempenho e eficiência, assim como de redução de impactos associados a áreas urbanizadas, que têm sido reconhecidos, local e internacionalmente, como referências em desenvolvimento urbano alinhado com critérios de sustentabilidade. A implantação de Vauban foi concluída em 2008, e o bairro conta com 38 hectares (FRAKER, 2013) e cerca de 5.100 habitantes (FREY, 2011). Cidade Pedra Branca, por sua vez, ocupa uma área de 59 hectares, está em construção e deve ser concluída em 2025, quando terá 30 mil habitantes e 30 mil postos de trabalho (PEDRA BRANCA, 2014).
Pretende-se, dessa forma, analisar de forma comparativa parâmetros de planejamento e desenho urbano, adotados nos referidos casos práticos, assim como desafios enfrentados, identificando-se estratégias promissoras no contexto de desenvolvimento de áreas urbanas brasileiras.

\section{Análise comparativa multicriterial de estratégias em sustentabilidade urbana aplicadas aos bairros Cidade Pedra Branca e Vauban}

O presente trabalho foi desenvolvido com base em revisão bibliográfica, visitas em campo e consulta a alguns agentes envolvidos nos processos de desenvolvimento urbano dos bairros estudados: Vauban e Cidade Pedra Branca. As Figuras 1 e 2 mostram visões gerais do padrão de ocupação das duas áreas urbanas consideradas.

Foram inicialmente estudadas as relações sistêmicas dos bairros em questão, identificando-se os principais fluxos de recursos (água - potável, reúso, esgoto, pluvial; energia - elétrica e calor; resíduos - recicláveis e rejeitos) e os principais condicionantes de sustentabilidade, analisando-se fatores tecnológicos, econômicos, sociais e institucionais. Esses insumos foram utilizados como base para identificar parâmetros e indicadores de apoio à análise multicriterial comparativa pretendida. As visitas técnicas aos bairros estudados foram acompanhadas por um profissional indicado pela administração municipal, no caso de Vauban, e orientadas pelo corpo técnico da empresa empreendedora, no caso de Cidade Pedra Branca, com o intuito de orientar o conhecimento da área e obter informações complementares sobre cada um dos bairros.

\section{Figura 1 - Padrão de uso e ocupação do solo em Vauban (Freiburg, Alemanha), em 2012}
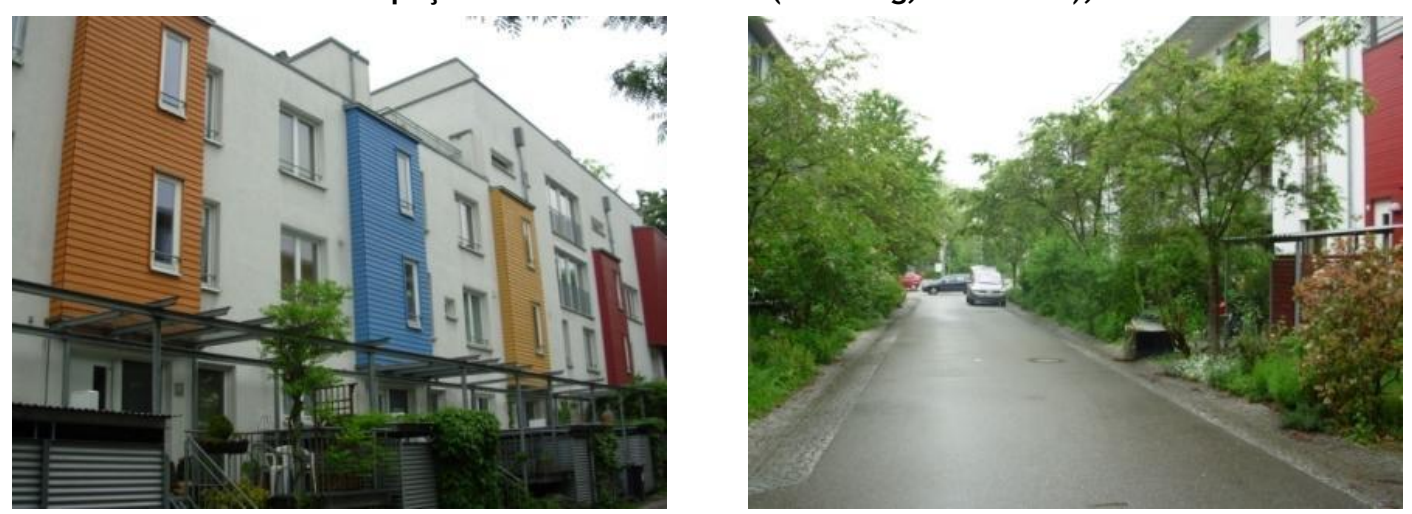
Figura 2 - Padrão de uso e ocupação do solo em Cidade Pedra Branca (Palhoça, Brasil), em 2014

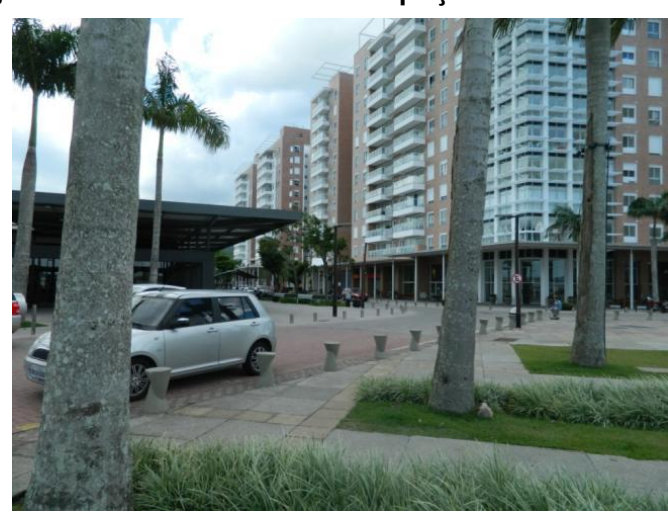

Para suportar e estruturar esse diagnóstico, os parâmetros e indicadores foram sistematizados em um quadro consolidado de apoio à análise multicriterial, organizado segundo diversos aspectos, entre eles governança, forma urbana, mobilidade e acessibilidade urbanas, e eficiência e suprimento energético, que são objeto do presente trabalho. A seguir são analisados os principais resultados da análise comparativa multicriterial, segundo os aspectos e critérios expostos.

\section{Governança}

Os aspectos relativos à governança são fundamentais desde a fase de planejamento até a de uso dos bairros, tocando tópicos relativos à propriedade da terra, às formas de participação dos atores, assim como a mecanismos de incorporação e execução dos empreendimentos, estabelecidos pelas municipalidades ou empreendedores (no caso de Cidade Pedra Branca). Verificou-se que as definições desses tópicos condicionam diretamente o tempo de planejamento e o de construção dos bairros, assim como influenciam o percentual dedicado à habitação de interesse social e os padrões de desempenho das edificações.

Nessa análise destaca-se primeiramente a questão da propriedade da terra versus padrão de desempenho pretendido ou alcançado. No caso de Vauban, a Prefeitura de Freiburg era a maior proprietária do solo e vendeu $70 \%$ dele a "grupos de proprietários", responsáveis pela construção dos edifícios para sua própria moradia (FREY, 2011). Segundo o autor, essa estratégia aumentou consideravelmente o tempo dedicado ao planejamento (3 anos) e, principalmente, à construção de Vauban (12 anos). Conforme indicado na Figura 1, múltiplos atores foram envolvidos nesse processo, ampliando as especificidades dos projetos e reduzindo a padronização de soluções. Por outro lado, a participação direta dos proprietários contribuiu para alcançar altos patamares de desempenho

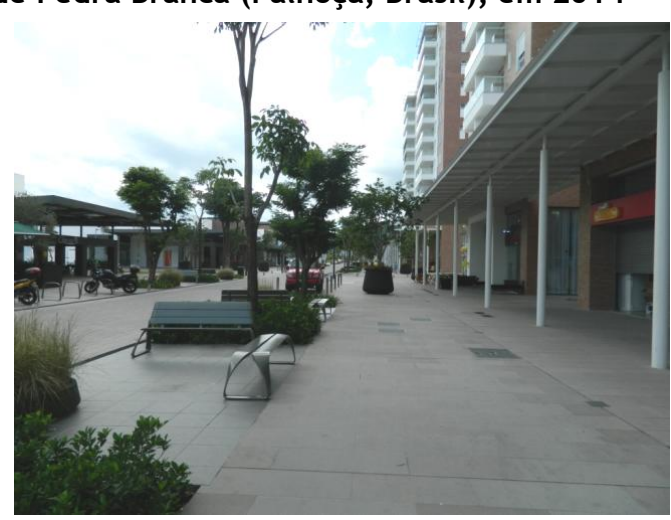

construtivo e energético, por meio do maior controle e exigência em projeto, construção e aprovação dos empreendimentos, assim como do monitoramento do desempenho deles.

Cidade Pedra Branca, por sua vez, é um bairro em desenvolvimento pela iniciativa privada. $\mathrm{O}$ desenvolvimento do projeto urbanístico foi apoiado por dinâmicas em grupo conhecidas por "charretes", as quais foram coordenadas pelo empreendedor. As charretes constituíram reuniões gerais dos atores envolvidos, para as quais foram convidados, além dos técnicos, representantes da comunidade, do poder público, de associações e universidades, entre outros. As charretes tiveram 15 dias de duração cada, nos quais os participantes (cerca de 40 pessoas) discutiram diversos pontos da proposta de desenvolvimento da área, sendo as diretrizes e soluções escolhidas por consenso, ou por $51 \%$ dos votos (BITTENCOURT, 2014). O tempo total de planejamento do bairro de Cidade Pedra Branca foi de 5 anos (PEDRA BRANCA, 2014), ou seja, proporcional a Vauban quando consideradas as respectivas áreas dos bairros, mas inferior se comparadas as populações finais de ambos os locais.

Um segundo ponto relevante se refere à institucionalização de um órgão interlocutor do empreendedor com a população. Nesse âmbito a instalação de um conselho consultivo ou comitê de assessoramento público em Vauban se mostrou relevante para a interação entre atores envolvidos e/ou atingidos pela implantação do empreendimento, estabelecendo um canal permanente para interlocução, sobretudo com a população (FREY, 2011). Em Vauban, o comitê de assessoramento teve importância adicional nos processos de planejamento, atuando de forma deliberativa e influenciando decisões. No caso de Cidade Pedra Branca não foi identificado um órgão oficial de interlocução do empreendedor com a comunidade, com exceção da equipe e instalações atuantes no stand de vendas do bairro, 
que também proporciona a consulta a informações sobre o projeto de urbanização e sobre os empreendimentos.

\section{Forma urbana}

A análise da forma urbana considerou principalmente parâmetros relativos à densidade urbana e ao uso e ocupação do solo, assim como condições gerais de desenho urbano.

Com relação à densidade urbana, analisou-se a densidade populacional residencial e também de empregos, tendo em vista obter valores comparativos quanto ao potencial de uso misto, assumindo-se que, quanto mais equilibrada é a relação de habitante por emprego, maior é a chance da área de desenvolver uma distribuição mais diversificada de usos do solo. Além disso, densidades populacionais (residencial + empregos) condicionam a capacidade dos sistemas de infraestrutura urbana, com destaque ao sistema de transporte. Em áreas com densidades populacionais mais altas, modos de transporte não motorizados e coletivos tendem a ser os mais viáveis.

Como mostra a Figura 4, em ambos os bairros identificou-se o adensamento populacional em relação aos valores médios das respectivas cidades onde estão inseridos: 134 habitantes/ha e 16 empregos/ha em Vauban (FREY, 2011) contra 65 habitantes/ha em Freiburg (FREY, 2011); e 508 habitantes/ha e 508 empregos/ha em Cidade Pedra Branca (calculado com base em Pedra Branca (2014)) contra 3 habitantes/ha em Palhoça (INSTITUTO..., 2010). Assim, o nível de adensamento populacional previsto em Cidade Pedra Branca, tanto para a população residente quanto para a população empregada, é bastante superior ao de Vauban.

O adensamento populacional ocorre pelo incremento de unidades habitacionais por área, pelo maior nível de verticalização e ocupação do solo, assim como pelo maior número de habitantes por unidade habitacional, conforme é possível verificar analisando-se os parâmetros reunidos na Tabela 1. A taxa de ocupação, o coeficiente de aproveitamento, o número médio de pavimentos e a densidade de unidades habitacionais indicam aspectos de densidade populacional associada à densidade construída, que também é bastante superior no caso de Cidade Pedra Branca. Por outro lado, embora seja mencionado o incentivo ao uso misto em Vauban, verifica-se que o uso do solo nesse caso é primordialmente residencial. Planejou-se uma participação maior de empregos em Cidade Pedra Branca, que demandaria incremento construtivo destinado a comércio e serviços, o que de fato ainda não pôde ser constatado porque o bairro está em construção.

Outro ponto diz respeito à distribuição de áreas construídas e áreas livres e verdes, conforme representado nos gráficos das Figuras 3 e 4 . Os valores são baseados em dados apresentados por Fraker (2013) e Pedra Branca (2014), e em medições de áreas indicadas em projeto e em sistema georrefenciado Google Earth (2014a).

Com relação a esse aspecto, verifica-se em Vauban a priorização de áreas livres e de uso predominantemente público e coletivo para convívio social, lazer, transporte não motorizado e adequação microclimática, as quais constituem cerca de $75 \%$ do território total do bairro. Reconhece-se assim a busca por um equilíbrio entre as especificações para adensamento e ocupação do solo, valorizando-se mutuamente espaço construído e espaço livre, este integrado ao sistema de áreas verdes. Conclui-se que essa diretriz é em parte resultante do modelo de governança adotado, relacionado à coordenação de desenvolvimento urbano pelo poder público associado a grupos de proprietários, provavelmente os mais interessados em aspectos qualitativos no longo prazo.

Tabela 1 - Parâmetros e indicadores de morfologia urbana

\begin{tabular}{l|c|c|c}
\hline \multicolumn{1}{c|}{ Parâmetros e indicadores } & Unidade & Vauban & C.P. Branca \\
\hline Uso residencial & $\%$ & $82^{1}$ & $65^{5}$ \\
Uso comercial & $\%$ & $18^{1}$ & $35^{5}$ \\
Taxa de ocupação & $\%$ & $50^{2}$ & $80^{5}$ \\
Coeficiente de aproveitamento & - & $1.4^{2}$ & $4.7^{5}$ \\
Número médio de pavimentos & Pavimentos & $4^{3}$ & $12^{5}$ \\
Densidade de unidades habitacionais & Unidades/ha & $53^{4}$ & $169^{6}$ \\
Habitantes por unidade habitacional & inhab./unid & $2.55^{3}$ & $3.37^{6}$ \\
\hline
\end{tabular}

Nota: ${ }^{1}$ baseado em Fraker (2013); ${ }^{2}$ Bube (2010); ${ }^{3}$ baseado em Frey (2011); ${ }^{4}$ Frey (2011); ${ }^{5}$ Pedra Branca (2014); e baseado em Pedra Branca (2014). 
Figura 3 - Duração do planejamento e implantação dos bairros

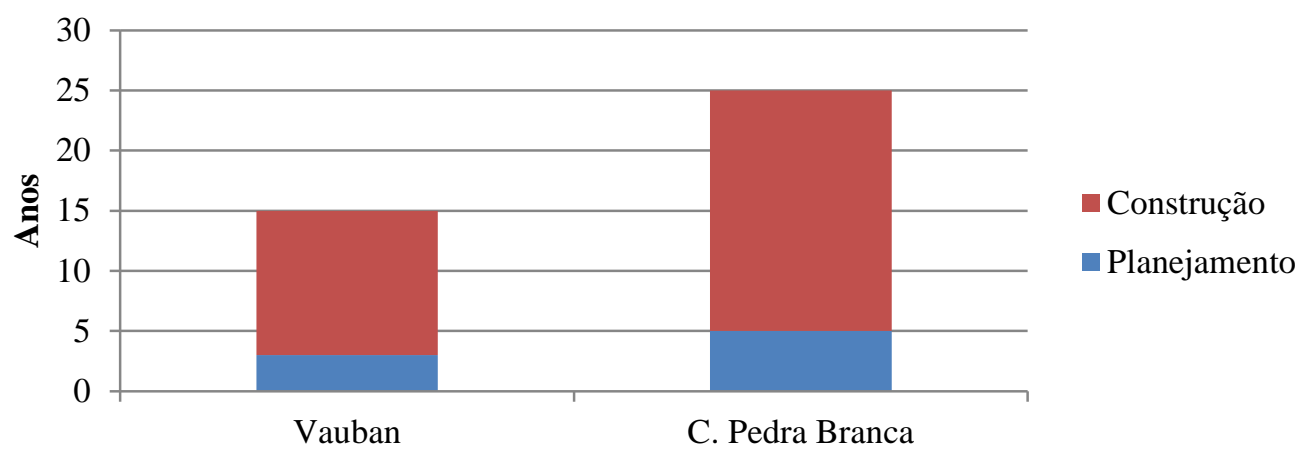

Figura 4 - Densidades populacionais e de empregos

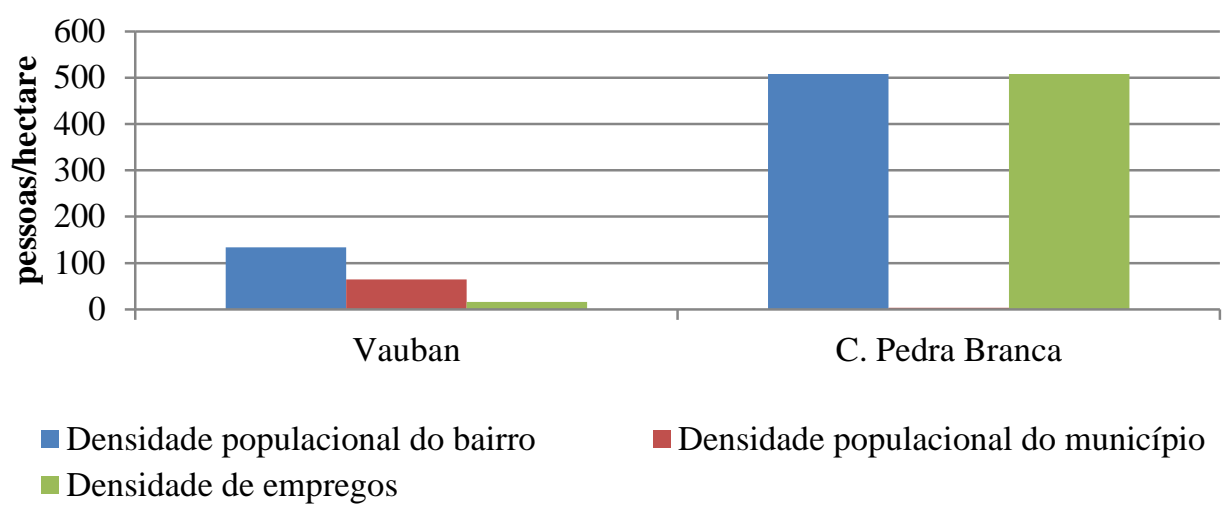

Figura 5 - Distribuição de áreas urbanas nos bairros estudados

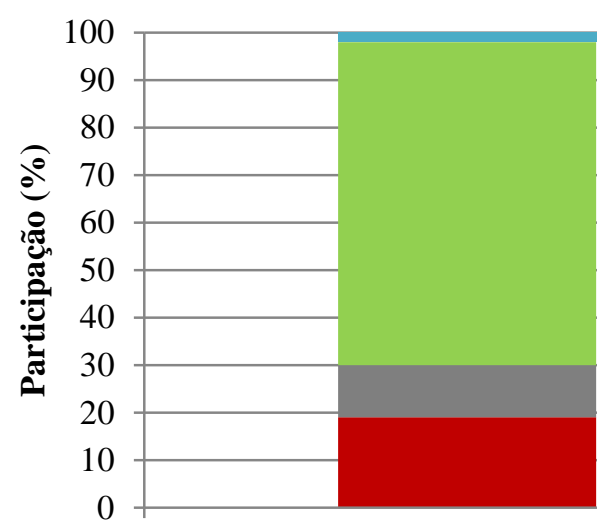

Vauban

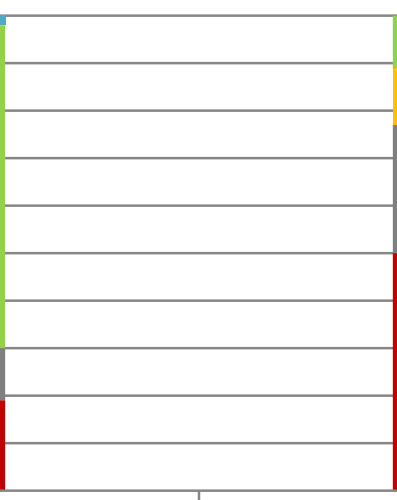

C. Pedra Branca

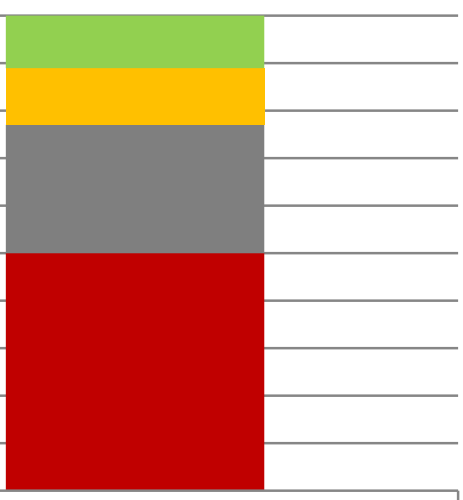

- Área ocupada por edifícios

Área livre nas quadras

- Área com espelho d'água
- Área ocupada por s. viário/ estac. superficial - Área verde 
Figura 6 - Distribuição de áreas livres e públicas nos bairros estudados

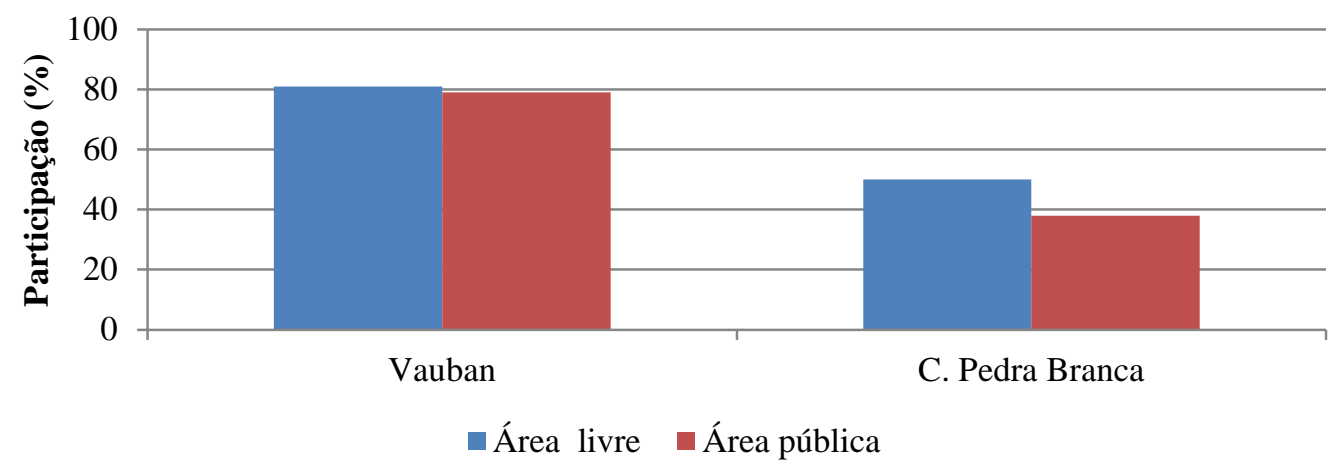

No caso da Cidade Pedra Branca o elevado nível de adensamento populacional e de empregos pretendido demandou o aumento da densidade construída. Nesse caso, as áreas públicas e livres, embora qualificadas e projetadas no conjunto do bairro, são reduzidas aos limites da legislação brasileira de parcelamento do solo, sendo inferiores, em termos quantitativos, às respectivas áreas adotadas no caso de Vauban.

Do ponto de vista formal e do desenho urbano, em Cidade Pedra Branca foi definida uma estrutura urbana que privilegia o pedestre, ao contar com calçadas mais largas, dispositivos de traffic calming e valorização de mobiliário urbano. As quadras foram projetadas para conter pátios internos, a serem compartilhados pelos usuários dos prédios nelas implantados, portanto de uso privativo. Os empreendimentos não devem ter muros, o que é um diferencial com relação aos modelos comumente em implantação em cidades brasileiras. Do ponto de vista volumétrico, os edifícios devem ter três partes claramente definidas - base sem pilotis (acesso público), corpo (uso privativo) e coroamento (arremate da cobertura). Garagens devem ser situadas integralmente no subsolo. Além disso, os materiais das vedações externas devem se aproximar ao padrão de tijolos aparentes, para identidade visual do conjunto construído no bairro (BITTENCOURT, 2014).

O plano urbanístico de Vauban, por sua vez, foi baseado em soluções tradicionais de estruturação urbana na Europa no que diz respeito à definição dos gabaritos de altura das edificações (2 ou 3 pavimentos, além do térreo). Um importante diferencial é a integração de áreas verdes e naturais às áreas construídas, com baixas taxas de ocupação do solo, resultando em densidade populacional moderada e grande quantidade de áreas livres permeáveis e majoritariamente públicas. Ao longo do eixo viário principal do distrito foram estabelecidas cinco áreas verdes principais, projetadas por arquitetos paisagistas, entendidas como "[...] pequenas incursões da natureza no espaço urbano [...]”, também desempenhando importante função na ventilação urbana (FREY, 2011, p. 109-110). Nesse eixo, que também representa a via principal, está ainda localizada a linha de veículo leve sobre trilhos, que comunica o distrito ao centro de Freiburg, onde há, também, valetas e canais de infiltração e drenagem, que atuam como importantes áreas de infiltração de água de chuva (PHILIP, 2012).

Outra característica que diferencia Vauban é que, apesar de o padrão volumétrico pouco variar, o envelope (fachadas, aberturas, coberturas) das edificações é bastante diverso quanto ao leiaute e, principalmente, quanto à grande variedade de materiais e cores empregadas. Geralmente, as coberturas abrigam telhados-verdes, algumas vezes combinados com painéis solares. Nos materiais externos das fachadas predominam materiais renováveis, como madeira e aço, selecionados com base em extenso levantamento efetuado por membros do Vauban Forum, este financiado por um programa ambiental com suporte da União Europeia (FREY, 2011).

\section{Acessibilidade e mobilidade urbanas}

Os níveis de acessibilidade e mobilidade foram analisados com base na localização dos bairros nos respectivos municípios e também na região de influência. Foram ainda consideradas as condições de conectividade e transporte, segundo fatores de influência, tais como uso e ocupação do solo, desenho urbano e condições de acessibilidade aos sistemas de transporte disponíveis. A Tabela 2 reúne os principais parâmetros considerados nessa análise.

Como é mostrado na Tabela 2, Vauban foi implantado mais próximo das demais áreas urbanizadas e consolidadas, assim como do centro da cidade de Freiburg. Dessa forma, sua própria inserção urbana e regional já amplia as condições 
de acessibilidade urbana. Cidade Pedra Branca, por sua vez, está localizada em Palhoça, que integra a Grande Florianópolis, distando $18 \mathrm{~km}$ do centro metropolitano, e terá a população de um pequeno município brasileiro, cerca de 30 mil habitantes. $\mathrm{O}$ bairro foi planejado para oferecer número de empregos igual ao de habitantes, o que deve favorecer modos de transporte não motorizados para acesso local. No entanto, do ponto de vista regional e macrourbano, há certamente um impasse no que se refere à acessibilidade $\mathrm{e}$ mobilidade urbana e metropolitana para os residentes ou frequentadores da área. O sistema viário e rodoviário já é congestionado antes da implantação do bairro, e não foi prevista, em projeto, alternativa de transporte de massa. Assim, é possível que se crie dependência do automóvel em deslocamentos para fora do bairro, estes, porém, subjugados a frequentes e intensos congestionamentos viários.

Dessa forma, e considerando os valores de divisão de modos de transporte indicados na Tabela 2, verifica-se que há predominância em Vauban do transporte a pé, por bicicleta e por transporte coletivo, compondo cerca de $83 \%$ das viagens, segundo uma pesquisa feita com 50 moradores do bairro em 2009 (SCHEURER; NEWMAN, 2009). Segundo a mesma pesquisa, cada pessoa faz em média 166 viagens de transporte público por ano, o que era a metade da média da cidade de Freiburg (STADT FREIBURG, 2008 ${ }^{2}$ apud SCHEURER; NEWMAN, 2009). Já Cidade Pedra Branca não dispõe de nenhuma pesquisa específica de transporte urbano, sendo considerada neste trabalho a divisão média de modos de transporte para cidades brasileiras entre 500 mil e 1 milhão de habitantes, entre as quais se enquadra Florianópolis (ASSOCIAÇÃO..., 2012). Segundo esses dados, a participação do automóvel é superior ao dobro de Vauban, valor esse que pode ser ainda superior no caso de Cidade Pedra Branca, devido aos motivos anteriormente expostos.

As condições de mobilidade e acessibilidade locais ainda são fortemente influenciadas pelo padrão de desenho urbano e pelas condições de uso do espaço urbano nos bairros considerados.

Do ponto de vista local, Vauban foi concebido para ser um bairro sem automóveis, "a car-free living project", o que constitui um diferencial da área, já que essa premissa não é encontrada em outros distritos de Freiburg (FREY, 2011). Para isso, o bairro incorpora infraestrutura adequada à caminhada e ao transporte cicloviário (caminhos verdes, vias dedicadas a pedestres e ciclistas, velocidade máxima de $30 \mathrm{~km} / \mathrm{h}$ no bairro), estando igualmente conectado à rede de transporte público de forma eficiente e atrativa, inclusive do ponto de vista econômico. Além disso, há restrições severas ao uso do transporte individual, sobretudo quanto à disponibilidade de espaço (não há vagas de estacionamento junto às edificações, vias são priorizadas para pedestres, ciclistas e transporte público) e cobrança de estacionamento (há poucas vagas, as existentes tem valor elevado e demandam autorização), o que ratifica o foco do bairro no uso dos modos não motorizados e coletivos de transporte.

Cidade Pedra Branca também mostra diversas soluções que pretendem suportar e favorecer o transporte a pé ou por bicicleta no interior do bairro. As calçadas são mais largas, e o leito carroçável, mais estreito, valorizando-se, na escala do pedestre, aspectos de ergonomia urbana, padronização visual e de mobiliário urbano, o que constitui um diferencial do bairro com relação à realidade brasileira. As vias são, ainda, mais curtas que as vias tradicionais e interligam pequenas praças, onde está prevista a instalação de comércio e serviços, acessíveis por uma caminhada de 5 a 10 min. Entretanto, essa estrutura poderia ser ainda potencializada se conectada aos modos coletivos de transporte, favorecendo, assim, a integração do bairro com o entorno ou a região de forma mais estruturada.

O gráfico da Figura 7 sumariza parâmetros selecionados de mobilidade e acessibilidade urbana para os dois bairros em questão. Os pesos adotados são ilustrativos e derivam dos valores apresentados na Tabela 2. Quanto menor a área do polígono, melhor é o desempenho do bairro com relação a aspectos de mobilidade e acessibilidade urbanas.

Assim, a análise dos casos mostra que o sucesso de uma divisão de modos de transporte mais equilibrada e com menores impactos ambientais, sociais e econômicos depende da implementação de um conjunto de estratégias e soluções articuladas que permitam maior acessibilidade e conectividade do bairro com sua região de inserção, controlando o transporte individual e oferecendo tarifas mais atrativas de transporte público, entre outros aspectos relevantes. Assim, fica evidente no caso de Vauban a importância da combinação de ações para ampliar e melhorar as condições de mobilidade urbana por meio de alternativas ao transporte individual. 
Tabela 2 - Parâmetros e indicadores de mobilidade e acessibilidade urbanas

\begin{tabular}{|c|c|c|c|}
\hline Parâmetros e indicadores & Unidade & Vauban & C.P. Branca \\
\hline Distância do bairro ao centro da cidade & $\mathrm{km}$ & $3^{1}$ & $18^{1}$ \\
\hline $\begin{array}{l}\text { Tempo de viagem ao centro da cidade de transporte } \\
\text { público }\end{array}$ & $\min$ & $15^{1}$ & $43,2^{1}$ \\
\hline $\begin{array}{l}\text { Distância média das unidades residenciais ao ponto de } \\
\text { acesso ao transporte público }\end{array}$ & $\mathrm{m}$ & $300^{3}$ & $500^{2}$ \\
\hline Viagens a pé & $\%$ & & $40^{12}$ \\
\hline Viagens de bicicleta & $\%$ & & $3^{12}$ \\
\hline Viagens de automóveis & $\%$ & $16^{4}$ & $34^{12}$ \\
\hline Viagens de transporte público & $\%$ & $19^{4}$ & $22^{12}$ \\
\hline Taxa de motorização & veículos/1.000 hab & $150^{5}$ & $667^{9}$ \\
\hline Vagas de estacionamento por unidade habitacional & Vagas/unid & $0,5^{6}$ & $1,5^{10}$ \\
\hline Velocidade de tráfego nas vias principais & $\mathrm{km} / \mathrm{h}$ & $30^{7}$ & $40^{10}$ \\
\hline Tarifa de transporte público & euros & $2,2^{8}$ & $1,4^{11}$ \\
\hline
\end{tabular}

Nota: ${ }^{1}$ Googlemaps (2014); ${ }^{2}$ Google Earth (2014b); ${ }^{3}$ Fraker (2013); ${ }^{4}$ Scheurer e Newman (2009), baseado em uma pesquisa com 50 habitantes do bairro de Vauban; ${ }^{5}$ Fórum Vauban $\left(2009^{3}\right)$ apud Buehler e Pucher (2011); ${ }^{6}$ Gorges (2011); ${ }^{7}$ City of Freiburg im Breisgau (2008); ${ }^{8}$ Freiburger Verkehrs AG (2014); ${ }^{9}$ calculado considerando 1,5 vaga por unidade residencial, de acordo com Pedra Branca (2014). ${ }^{10}$ Pedra Branca (2014); ${ }^{11}$ Sindicato... (2014); e ${ }^{12}$ assumido com base na divisão média de modos de transporte, para cidades brasileiras entre 500 mil e 1 milhão de habitantes, entre as quais se enquadra Florianópolis, de acordo com Associação Nacional dos Transportes Públicos (2012).

\section{Figura 7 - Estratégias em acessibilidade e mobilidade urbanas nos bairros estudados}

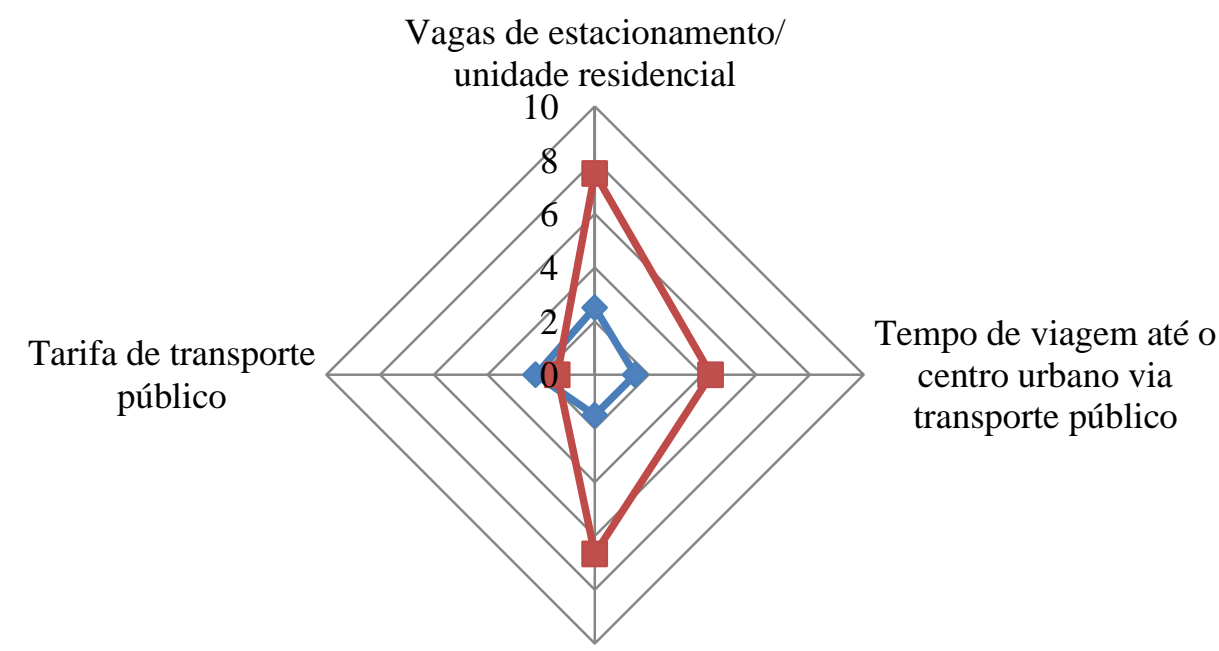

Taxa de motorização

$\sim$ Vauban $\quad$ C. Pedra Branca

${ }^{3}$ FORUM VAUBAN. Planning a Sustainable Community. Freiburg: Forum Vauban, 2009. 


\section{Eficiência energética e fornecimento de energia}

Foram considerados no escopo da análise os fatores determinantes e os níveis de consumo de energia em transporte urbano e edifícios residenciais, além de sistemas de geração e fornecimento local de energia elétrica e térmica.

O consumo de energia em transportes por passageiro transportado e por ano não pôde ser obtido diretamente nas bases de informações consultadas. Foi então realizada uma estimativa de consumo baseada na metodologia descrita em Marins e Roméro (2013). Para isso foi considerada a divisão modal de transporte indicada na Tabela 4, associada aos seguintes parâmetros e indicadores:

(a) consumo de energia por tecnologia veicular e combustível, em MJ/passageiro-km:

- 0,48 para ônibus (COMPANHIA..., 1998);

- 0,79 para veículo leve sobre trilhos (NEWMAN; KENWORTHY, 1999);

- 3,21 para automóveis a gasolina (COMPANHIA..., 1998);

- 4,49 para automóvel a etanol (assumido, de acordo com a eficiência no consumo do combustível, em relação a veículos à gasolina); e

- 1,80 para automóveis a diesel (NYLUND, 2013).

(b) índice de mobilidade: 3,50 viagens por pessoa por dia em Vauban - média de valores calculada com base em Transport for London (2009), Transport of Department (2011) e Technical University of Denmark (2014) - e 1,67 viagem por pessoa por dia em Cidade Pedra Branca assumido com base no valor médio de viagens diárias por pessoa em cidades brasileiras com 500 mil a 1 milhão de habitantes, Região

Metropolitana de Florianópolis, de acordo com a Associação Nacional de Transportes Públicos (2012);

(c) ocupação média veicular em pessoas por veículo:

- 38 pessoas por ônibus (EMPRESA

METROPOLITANA..., 2008); e

- 123 em tram (ASSOCIAÇÃO..., 2004) e 1,5 em automóveis (ASSOCIAÇÃO..., 2009);

(d) período de operação dos sistemas de transporte (assumido): 300 dias por ano e $20 \mathrm{~h}$ por dia;

(e) distância média por viagem (assumida):

- 1 km para caminhada;
- $3 \mathrm{~km}$ para transporte cicloviário; e

- a distância entre o centro do bairro e o centro urbano para transporte público e automóveis $(3 \mathrm{~km}$ para Vauban e $18 \mathrm{~km}$ para Cidade Pedra Branca, esta com relação a Florianópolis).

(f) combustíveis utilizados (assumido):

- 50\% diesel $/ 50 \%$ gasolina em Vauban e 50\% gasolina/50\% etanol em Cidade Pedra Branca para automóveis; e

- 100\% diesel em ônibus e 100\% de eletricidade em veículo leve sobre trilhos.

(g) demanda total de transporte: número de residentes + número de empregados.

Os resultados mostram que, segundo a estimativa realizada, Cidade Pedra Branca consumiria anualmente cerca de 20 vezes mais de energia no transporte (considerando todos os modos) do que Vauban, conforme indicado na Figura 8, para atender a 97.194 passageiros por dia, contra 21.443 passageiros por dia em Vauban. Verifica-se, dessa forma, que as populações situadas em áreas mais distantes e dependentes do automóvel necessitarão de energia suplementar significativa para realizar suas viagens, conforme verificado em Cidade Pedra Branca. Por outro lado, áreas que implantaram políticas integradas visando ao incentivo do transporte não motorizado e do transporte público, com restrições físicas e econômicas ao transporte individual, como no caso de Vauban, tiveram o consumo médio de energia por passageiro transportado bastante reduzido. Identifica-se, assim, uma relação direta entre o consumo de energia em transporte urbano e as soluções de acessibilidade e mobilidade, que, por sua vez, são também condicionadas por fatores urbanísticos e de planejamento urbano (distância/dependência com relação ao centro urbano, por exemplo).

A Figura 9, por sua vez, mostra dados referentes ao consumo de energia em edifícios residenciais nos bairros estudados e respectivos valores médios encontrados na região de sua inserção.

Vauban diminuiu seu consumo energético total em edificações em cerca de $64 \%$, quando comparado ao consumo médio em edifícios convencionais em Freiburg, passando de 220 para $80 \mathrm{kWh} / \mathrm{m}^{2}$ por ano (LEVINE; ÜRGE-VORSATZ, 2007; FRAKER, 2013). Esse nível de eficiência foi alcançado mediante adoção obrigatória de padrões de desempenho em edificações e controle do desenvolvimento e aprovação de projetos, assim como da execução das obras e entrega/monitoramento do desempenho dos empreendimentos (FREY, 2011). Os edifícios 
seguem basicamente o padrão estabelecido pela Prefeitura de Freiburg em 1992 (LHE - Low Energy Houses), relativamente ao consumo máximo de $65 \mathrm{kWh} / \mathrm{m}^{2}$ por ano, com aquecimento ambiental e consumo total de energia de 200 $\mathrm{kWh} / \mathrm{m}^{2}$ por ano. Para tanto, a Prefeitura exige a adição de uma cláusula a todos os contratos imobiliários e descreve tal exigência. Embora os níveis básicos de consumo energético exigidos em Vauban (NEH) se refiram ao padrão adotado em Freiburg desde 1992, as prescrições são bastante semelhantes à legislação federal alemã atualizada em 2009, o que demonstra a antecipação de soluções pela Prefeitura local com relação a esses padrões (FREY, 2011).

Há em Vauban, ainda, 200 "habitações passivas", que visam ao menor consumo de energia possível (menos de $15 \mathrm{kWh} / \mathrm{m}^{2}$ por ano - Frey (2011)) para provimento de conforto térmico. Essas se caracterizam por aprimoramentos adicionais nos sistemas de isolamento térmico, vedação contra a infiltração de ar, uso de vidros triplos, além de orientação dos edifícios e localização de vegetação, visando otimizar o aquecimento solar passivo no inverno. Também estão presentes dispositivos de recuperação de calor no sistema de exaustão de ar, visando pré-aquecer o ar exterior antes de sua entrada nas edificações. Além disso, as habitações passivas geram mais energia elétrica do que consomem devido aos painéis fotovoltaicos instalados na cobertura (PHILIPP, 2012). Para atender aos requisitos das habitações passivas, o plano urbanístico de Vauban precisou ser revisado, para que as edificações tivessem o alinhamento na direção leste-oeste e a maximização das faces voltadas ao sul (mais adequada do ponto de vista climatológico no caso do hemisfério norte), para geração de calor e eletricidade. Segundo Frey (2011), havia certa falta de experiência na época, mesmo entre arquitetos, sobre a implantação dos novos padrões de eficiência energética, o que exigiu efetuar as revisões.

Para Cidade Pedra Branca não foram identificados valores de consumo médio das edificações residenciais nem obtidos valores planejados junto ao empreendedor. O consumo médio de energia em edifícios residenciais no Brasil, por sua vez, é da ordem de $40 \mathrm{kWh} / \mathrm{m}^{2}$ por ano, conforme indicado na Figura 9 (EMPRESA DE PESQUISA..., 2008; FUNDAÇÃO..., 2007), bastante inferior ao alemão e europeu, devido, sobretudo, à ausência de aquecimento ativo das edificações na maior parte do país.

Figura 8 - Consumo anual de energia em transporte urbano nos bairros estudados

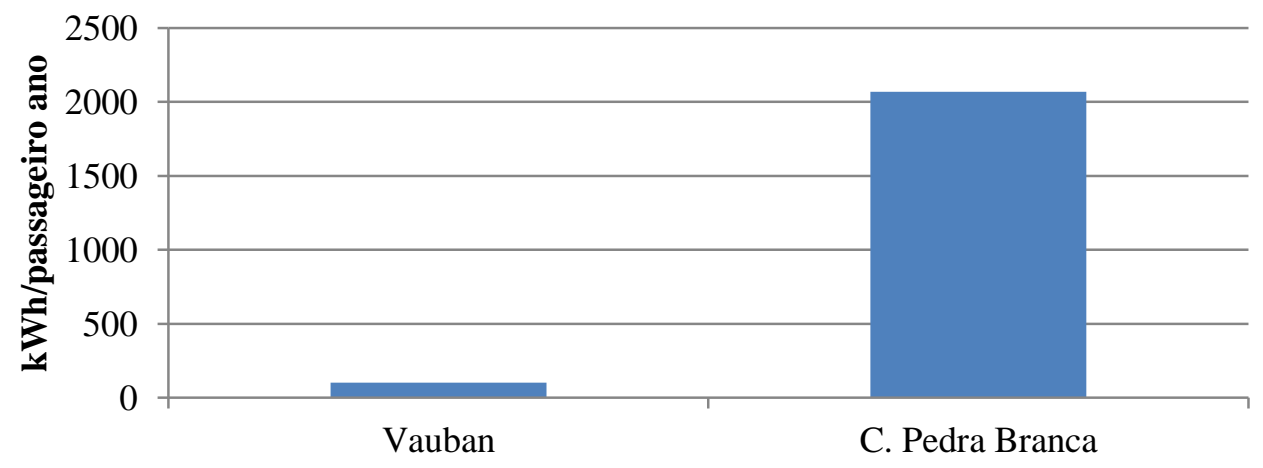

Figura 9 - Consumo de energia em edificações residenciais nos bairros estudados

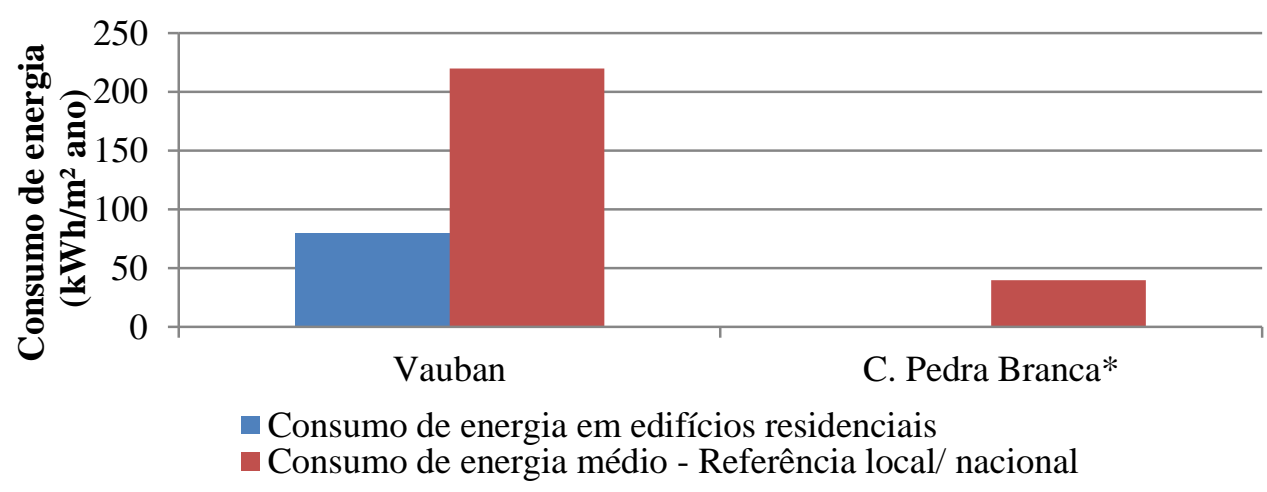


Essa relação também é observada quando se compara o consumo de energia em edificações por habitante por ano. Tomando por base os valores de consumo energético por área $\left(\mathrm{kWh} / \mathrm{m}^{2}\right.$ por ano), assim como a área construída total de edificações residenciais (FRAKER, 2013; PEDRA BRANCA, 2014) e a população total em ambos os bairros (FREY, 2011; PEDRA BRANCA, 2014), estimouse um consumo per capita em edificações em torno de $1.696 \mathrm{kWh} / \mathrm{hab}$ por ano em Cidade Pedra Branca e em torno de $2.820 \mathrm{kWh} / \mathrm{hab}$ por ano em Vauban, neste último caso já considerando a energia utilizada em aquecimento ambiental. É importante observar que o custo da energia na Alemanha é superior ao custo no Brasil (COMISSÃO..., 2013; CENTRAIS, 2014), o que também pode contribuir para o estabelecimento e a prática eficiente de políticas de eficiência energética.

As estratégias e soluções para eficiência energética em edificações planejadas e colocadas em prática em Vauban reduziram a demanda de energia e a respectiva capacidade instalada de geração. Dessa forma, o investimento simultâneo em geração de energia local baseada em fontes renováveis foi facilitado. Como mostra a Figura 10, foram implantados sistemas fotovoltaicos e cogeração à biomassa, com ligação para a rede de aquecimento distrital, que perfazem $90 \%$ do fornecimento energético local (MTU..., 2010; FRAKER, 2013). Com relação à Cidade Pedra Branca, foram instalados painéis fotovoltaicos no stand de vendas dos empreendimentos do bairro. Entretanto, entende-se que tal sistema não configura uma solução de geração de energia distrital, pois é destinado a uma edificação de pequeno porte, com uso específico. Para este bairro sistemas de aquecimento solar de água foram planejados para instalação no topo dos edifícios, sendo complementados por sistemas de aquecimento a gás. No entanto, a capacidade instalada prevista não pôde ser identificada e, portanto, a participação de renováveis não pode ser contabilizada no gráfico da Figura 10 (PEDRA BRANCA, 2010).

Finalmente, considerando o consumo total de energia em edificações residenciais e no transporte urbano de passageiros, segundo os parâmetros, indicadores e estimativas anteriormente expostos, tem-se um consumo total previsto de 2.910 $\mathrm{kWh}$ /pessoa por ano em Vauban e de 4.200 $\mathrm{kWh}$ /pessoa por ano em Cidade Pedra Branca, considerando tanto os residentes quanto os empregados. A diferença entre os bairros é resultado, sobretudo, do consumo de energia em transporte urbano, que no caso de Vauban é bastante reduzido em função da proximidade de pontos de origem e destino (bairro e centro) e da participação minoritária do automóvel. Embora superior a Vauban, o consumo em Cidade Pedra Branca é proporcionalmente reduzido em função, sobretudo, do elevado adensamento populacional, esperado tanto para residentes quanto para postos de trabalho, o que diminui o consumo estimado per capita. Além disso, o consumo energético em edificações neste bairro é menor em virtude de terem sido considerados valores médios de consumo energético no Brasil, nos quais a climatização artificial não é amplamente considerada.

Figura 10 - Geração de energia nos bairros estudados

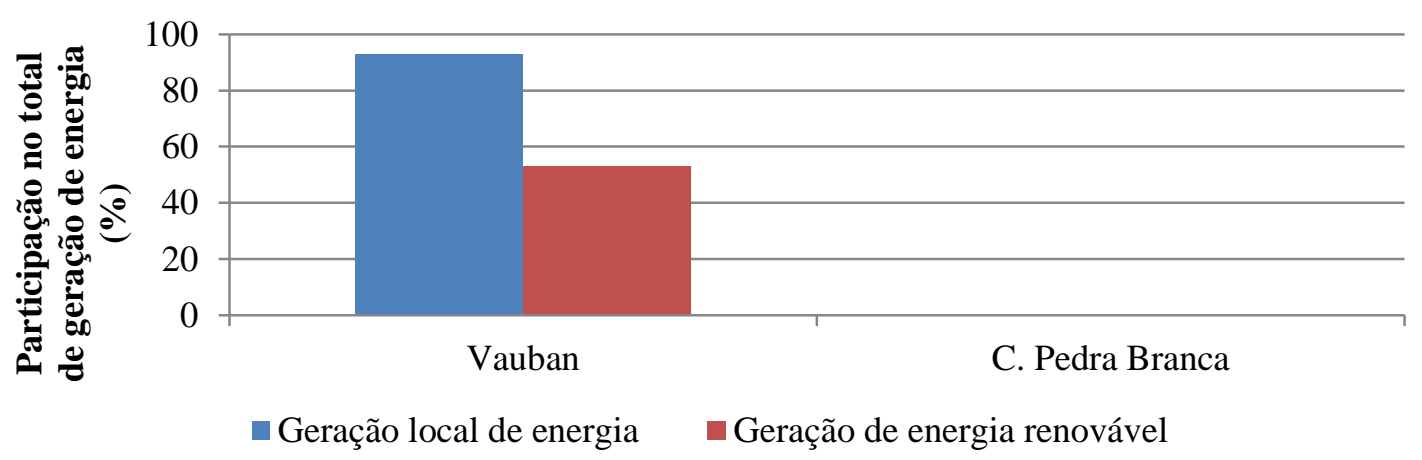

404 Marins, K. R. de C. C. 


\section{Sumarização das estratégias potenciais identificadas}

Com base na análise comparativa dos bairros de Vauban e Cidade Pedra Branca, as seguintes estratégias, entre as estudadas, se mostraram promissoras relativamente à promoção da sustentabilidade em projetos de desenvolvimento urbano:

(a) governança:

- coordenação dos processos de planejamento, projeto, execução e operação dos bairros, com definição e auditoria de metas e procedimentos; e

- criação de um canal/organismo permanente para interlocução e participação comunitária.

(b) forma urbana:

- adensamento populacional;

- planejamento multicriterial da quantificação e distribuição de áreas públicas e privadas, construídas e livres, considerando aspectos climatológicos, hidrológicos, sociais (áreas de lazer e convivência) e de mobilidade e acessibilidade, privilegiando os modos não motorizados de transporte; e

- uso misto (predomínio residencial, mas com a presença de comércio e serviços essenciais e incentivo a oportunidades de emprego no local).

(c) acessibilidade e mobilidade urbanas:

- planejamento do uso e ocupação do solo para motivar modos não motorizados e públicos de transporte;

- infraestrutura e projeto urbano adequados ao transporte a pé e cicloviário;

- acesso facilitado ao transporte público por meio da proximidade das moradias com as estações de embarque/desembarque, oferta de rede de transporte urbana e/ou regional que atenda aos desejos de viagens, com tarifa competitiva, bem como adequação do transporte não motorizado, entendido como alimentador essencial do transporte público; e

- controle do uso do transporte individual, com restrição de espaço para estacionamento e circulação viária, controle de velocidade de tráfego e cobrança de preços elevados no uso dos estacionamentos restritos.

(d) consumo e fornecimento energético:

- edificações com padrões superiores quanto ao desempenho ambiental e energético, consumindo menos energia do que edificações tradicionais;
- sistemas de geração de energia local, elétrica e térmica, em escala predial e também distrital. Incluem sistemas baseados em fontes renováveis (solar, eólica) e aproveitamento de calor de processo (resíduos, esgoto); e

- as estratégias para planejamento integrado do uso e ocupação do solo e do sistema de transporte urbano, com valorização de modos não motorizados e coletivos, também constituem uma estratégia de eficiência energética.

\section{Conclusões}

Este estudo objetivou identificar e analisar estratégias potenciais para incorporação de requisitos de sustentabilidade no desenvolvimento de áreas urbanas na escala de distritos, bairros e unidades de vizinhança.

A análise dos processos de desenvolvimento dos bairros de Vauban e Cidade Pedra Branca mostrou a importância de estabelecer mecanismos de planejamento e gestão transparentes, objetivos e com o nível de aprofundamento pertinente para diagnosticar as diferentes demandas e desenvolver as soluções necessárias, de forma adequada. O estudo dos processos de desenvolvimento mostrou, ainda, que é necessário integrar e gerir a participação efetiva de diferentes atores, assim como suportar a verificação e o monitoramento do desempenho e da qualidade das soluções adotadas ao longo do ciclo de vida do bairro. Dessa forma, coloca-se o desafio de estruturação e operação de um sistema de governança mais abrangente e permanente, compatível com cada realidade urbana.

A análise demonstrou ainda os benefícios associados à adoção de estratégias e soluções sistêmicas e intersetoriais, envolvendo uso e ocupação do solo e sistemas de infraestrutura, compatíveis com a escala de bairro e com as características de suas demandas, tais como "uso do solo, acessibilidade e mobilidade urbanas" e "eficiência energética em edificações e fornecimento energético local, utilizando fontes renováveis". As estratégias intersetoriais, embora demandem sofisticação e investimento em modelos de governança mais bem estruturados, podem viabilizar sistemas mais eficientes e que gerem menos impactos ambientais.

Finalmente, entende-se que o planejamento urbano na escala do bairro pode colaborar decisivamente para melhorar as condições de vida das comunidades urbanas e auxiliar na resolução dos problemas inerentes à administração municipal e setorial, tais como oferta de habitação, oportunidades de emprego e acesso e uso de 
recursos, como água e energia. Investir em desenho e projeto urbano, buscando definir parâmetros urbanísticos adequados a essa escala, é de suma importância. Para tanto, é necessário aprimoramento em regulação, assim como em processos decisórios e administrativos, e na estrutura organizacional, sobretudo municipal e em âmbito local, inclusive para viabilizar a especificação e o controle de tais parâmetros, assim como a instalação e gestão de sistemas interdependentes ou compartilhados por diferentes setores ou empreendimentos urbanos.

\section{Referências}

ASSOCIAÇÃO NACIONAL DE EMPRESAS DE TRANSPORTES E TRÂNSITO. Sistema Redes: construindo redes de transporte público de qualidade. Brasília: NTU, 2004.

ASSOCIAÇÃO NACIONAL DE TRANSPORTES PÚBLICOS. Sistema Nacional de Informações da Mobilidade Urbana: relatório geral 2008. São Paulo: ANTP, 2009.

ASSOCIAÇÃO NACIONAL DE TRANSPORTES PÚBLICOS. Sistema Nacional de Informações da Mobilidade Urbana: relatório geral 2011. São Paulo: ANTP, 2012.

BATTY, M. Cities as Complex Systems: scaling, interactions, networks, dynamics and urban morphologies. London: Centre for Advanced Spatial Analysis, University College London, 2008.

BERARDI, U. Sustainability Assessment in the Construction Sector: rating systems and rated buildings. Sustainable Development, v. 20, n. 6, p. 411-424, 2012.

BITTENCOURT, D. [Dados Fornecidos em Reunião Realizada em 26 de Fevereiro na Cidade Pedra Branca]. Palhoça: Pedra Branca, 2014.

BOURDIC, L.; SALAT, S.; NOWACKI, C. Assessing Cities: a new system of cross-scale spatial indicators. Building Research \& Information, v. 40, n. 5, p. 592-605, 2012.

BUBE, T. The Vauban Quarter in Freiburg, Germany. In: INTERNATIONAL FORUM FOR SUSTAINABLE HOUSING, Mexico City, 2010. Proceedings... Mexico: Institute of the National Housing Fund for Workers, 2010.

BUEHLER, R.; PUCHER, J. Sustainable Transport in Freiburg: lessons from Germany's environmental capital. International Journal of Sustainable Transportation, v. 5, n. 1, p. 43-70, 2011.
CENTRAIS ELÉTRICAS DE SANTA

CATARINA. Tarifas e Taxas de Energia. 2014.

Disponível em:

<http://portal.celesc.com.br/portal/atendimento>. Acesso em: 28 fev. 2014.

CITY OF FREIBURG IM BREISGAU.

Stadtplanungsamt: Verkehr (Traffic concept).

Freiburg: City of Freiburg im Breisgau, 2008.

COMISSÃO EUROPEIA. Electricity and

Natural Gas Price Statistics. 2013. Disponível em: <http://ec.europa.eu/eurostat/statisticsexplained/index.php/File:Half-

yearly_electricity_and_gas_prices,_second_half_o f_year,_2012\%E2\%80\%9314_\%28EUR_per_kWh \%29_YB15.png>. Acesso em: 20 fev. 2014.

COMPANHIA DO METROPOLITANO DE SÃO PAULO. Pesquisa Origem-Destino 1997. São Paulo: Metro, 1998.

DANIELL, K. A. et al. Integrated Urban System Modeling: methodology and case study using multi-agent systems. In: ZERGER, A.; ARGENT, R. M. (Eds.). International Congress on Modelling and Simulation, 2005. Proceedings... 2005.

EMPRESA DE PESQUISA ENERGÉTICA. Projeções da Demanda de Energia Elétrica Para o Plano Decenal de Expansão de Energia 2008-2017. Rio de Janeiro: EPE, 2008.

\section{EMPRESA METROPOLITANA DE}

TRANSPORTES URBANOS DE SÃO PAULO.

Relatório Mensal de Operação: outubro de 2008. São Bernardo do Campo: EMTU/SP, 2008.

ENGEL-YAN, J. et al. Toward Sustainable Neighbourhoods: the need to consider infrastructure interactions. Canadian Journal of Civil Engineering, v. 32, p. 45-57, 2005.

FRAKER, H. The Hidden Potential of Sustainable Neighbourhoods: lessons from lowcarbon communities. Washington: Island, 2013.

FREIBURGER VERKEHRS AG.

Preisinformationen. 2014. Disponível em: <http://www.vag-freiburg.de/ticketstarife/preisinformationen.html>. Acesso em: 20 mar. 2014.

FREY, W. Freiburg Green City. Freiburg: Verlag Herder, 2011.

FUNDAÇÃO SISTEMA ESTADUAL DE ANÁLISE DE DADOS. Dados estatísticos Sobre a RMSP - 2007. São Paulo: SEADE, 2007.

GOOGLE EARTH. [Quantificação de Áreas Ocupadas por Edificações, Livres, Viárias e Verdes, do Bairro de Vauban]. 2014a. 
GOOGLE EARTH. [Distância Percorrida e Tempo de Viagem de Vauban e Cidade Pedra Branca aos Centros Urbanos]. 2014b.

GOOGLEMAPS. [Distância Percorrida e Tempo de Viagem de Vauban e Cidade Pedra Branca aos Centros Urbanos]. Google, Brasil, 2014.

GORGES, T. “Quartier Vauban” Sustainable District in Freiburg, Germany. Eschborn: Deutsche Gesellschaft für Internationale Zusammenarbeit GmbH, 2011.

INSTITUTO BRASILEIRO DE GEOGRAFIA E ESTATÍSTICA. Sistema InfoCidades: Dados do Censo de 2010. 2010.

LEVINE, M.; ÜRGE-VORSATZ, D. Residential and Commercial Buildings. In: METZ, B. et al. (Eds.). Climate Change 2007: mitigation. Cambridge: Cambridge University Press, United Kingdom and New York, 2007.

MARINS, K. R. C. C.; ROMÉRO, M. A. Urban and Energy Assessment From a Systemic Approach of Urban Morphology, Urban Mobility, and Buildings: case study of Agua Branca, in Sao Paulo. Journal of Urban Planning and Development, v. 139, n. 4, p. 280-291, 2013.

MARINS, K. R. C. C.; ROMERO, M. A. Integração de Condicionantes de Morfologia Urbana no Desenvolvimento de Metodologia Para Planejamento Energético Urbano. Ambiente Construído, Porto Alegre, v. 12, n. 4, p. 57-73, out./dez. 2012.

MARTINARD, C. Le Génie Urbaine. Paris, 1986. Rapport au Ministre de l'Équipment, du Logement, de l'Aménagement du Territoireet des Transports. La documentation française.

MTU ONSITE ENERGY GMBH GAS POWER SYSTEMS. Cogeneration Power Plant in Vauban Achieves Efficiency of 96 Percent. Augsburg: MTU Onsite Energy GmbH Gas Power Systems, 2010.

NEWMAN, P.; KENWORTHY, J. An International Sourcebook of Automobile Dependence in Cities, 1960-1990. Niwot, Boulder: University Press of Colorado, 1999.

NG, Ed. (Ed.). Designing High-Density Cities. London: Earthscan, 2010.

NYLUND, N. O. Vehicle Energy Efficiencies. In: IEA EGRD Workshop Mobility: technology priorities and strategic urban planning. Espoo: IEA Experts' Group on R\&D Priority-Setting and Evaluation, 2013.

PEDRA BRANCA. Condomínio Pátio da Pedra: memorial descritivo. Florianópolis: Pedra Branca, 2010.
PEDRA BRANCA. Dados de projeto disponibilizados referentes ao planejamento e implantação do bairro Cidade Pedra Branca, registrados sob a forma de emails, formulário preenchido e projetos técnicos. Florianópolis: Pedra Branca, 2014.

PHILIPP. A. Informações fornecidas em visita técnica realizada ao bairro de Vauban em 23 de maio de 2012. Freiburg, 2012.

SCHEURER, J.; NEWMAN, P. Vauban: a european model bridging the green and brown agendas. Case study prepared for Revisiting Urban Planning: Global Report on Human Settlements, 2009. Disponível em:

<http://www.unhabitat.org/grhs/2009>. Acesso em: 15 jun. 2014.

SINDICATO DE EMPRESAS DE

TRANSPORTES URBANOS DE

PASSAGEIROS DA GRANDE

FLORIANÓPOLIS. Tarifas Municipais. 2014.

Disponível em: <http://www.setuf.com.br/facil/>. Acesso em: 20 jun. 2014.

TECHNICAL UNIVERSITY OF DENMARK. The Danish National Travel Survey. 2014

Disponível em:

<http://www.modelcenter.transport.dtu.dk/english/ TU>. Acesso em: 15 jul. 2014.

TRANSPORT FOR LONDON. Travel in London: report number I. London: Transport for London, 2009.

UNITED STATES DEPARTMENT OF

TRANSPORTATION. Summary of Travel

Trends: 2009 National Household Travel Survey. Washington: US Department of Transportation, 2011.

WALTON, D. et al. Urban Design

Compendium. London: English Partnerships e

The Housing Corporation, 2007.

WHEELER, S. Planning for Sustainability. $2^{\text {nd }}$. ed. New York: Routledge, 2013.

YANG, W.; WONG, N. H.; JUSUF, S. K.

Thermal Comfort in Outdoor Urban Spaces in Singapore. Building and Environment, n. 59, p. 426-435, 2013.

\section{Agradecimentos}

À Fundação de Amparo à Pesquisa do Estado de São Paulo (Fapesp), pelo apoio recebido para o desenvolvimento da pesquisa (Processo $\mathrm{n}^{\mathbf{0}}$ 2011/21315-4). 
À equipe técnica da Cidade Pedra Branca, em especial aos engenheiros Ramiro Nilson e Dilnei Bittencourt, pela disponibilização de dados.

\section{Karin Regina de Casas Castro Marins}

Departamento de Engenharia de Construção Civil, Escola Politécnica | Universidade de São Paulo | Av. Prof. Almeida Prado, trav. 2, n 83, Cidade Universitária | São Paulo - SP - Brasil | CEP 05508-070 | Tel.: (011) 3091-5107 | E-mail: karin.marins@poli.usp.br

\section{Revista Ambiente Construído}

Associação Nacional de Tecnologia do Ambiente Construído

Av. Osvaldo Aranha, $99-3^{\circ}$ andar, Centro

Porto Alegre - RS - Brasil

CEP $90035-190$

Telefone: +55 (51) 3308-4084

Fax: +55 (51) 3308-4054

www.seer.ufrgs.br/ambienteconstruido

E-mail: ambienteconstruido@ufrgs.br

408 Marins, K. R. de C. C. 